\title{
Analytical modelling of continuous fibre-reinforced thermoplastics' thermomechanical properties and implementation into a failure model
}

\author{
Norbert Schramm ${ }^{1)}$, Jan Xaver Teltschik²), Lothar Kroll2) \\ 1) LSE - Lightweight Structures Engineering GmbH, norbert.schramm@lse-chemnitz.de, Otto- \\ Schmerbach-Straße 19, 09117 Chemnitz, Germany \\ 2) Department of Lightweight Structures and Polymer Technology, slk@mb.tu-chemnitz.de, \\ Chemnitz University of Technology, Reichenhainer Straße 31/33, 09126 Chemnitz, Germany
}

\section{Keywords}

Fibre-reinforced Thermoplastics, Tape Material, Temperature-dependent Mechanical Properties, Physically Based Failure Criterion, Analytical Modelling.

\begin{abstract}
Mechanical properties of fibre-reinforced thermoplastics show a remarkable temperature dependence within application temperatures of automotive and aerospace lightweight structures. To take this dependence into account when designing components, the strengths $\left(\mathrm{R}_{\|}{ }^{\mathrm{t}}, \mathrm{R}_{\|}{ }^{\mathrm{c}}, \mathrm{R}_{\perp}{ }^{\mathrm{t}}, \mathrm{R}_{\perp}{ }^{\mathrm{c}}, \mathrm{R}_{\perp \|}\right)$ and stiffnesses $\left(\mathrm{E}_{\|}{ }^{\mathrm{t}}, \mathrm{E}_{\|}{ }^{\mathrm{c}}, \mathrm{E}_{\perp}{ }^{\mathrm{t}}, \mathrm{E}_{\perp}{ }^{\mathrm{c}}, \mathrm{G}_{\perp \|}\right)$ of continuous carbon and glass fibre-reinforced polyamide 6 and glass fibre-reinforced polypropylene are modelled analytically based on experiments. Data from temperaturecontrolled tests on flat samples in the range from $-20^{\circ} \mathrm{C}$ to $+80^{\circ} \mathrm{C}$ are therefore approximated using an extended hyperbolic approach. The models obtained are then evaluated based on their deviation from the experimental values. The main criterion of this evaluation is the reliable prediction of the temperature-dependent material properties while minimising the effort for generating test data and determining model parameters. Furthermore, the failure behaviour of the investigated materials under multiaxial mechanical and thermal stress is examined by implementing the determined strength curves into Cuntze's physically based failure criterion.
\end{abstract}

\section{Introduction}

\subsection{Analytical model for the temperature-dependent strength and stiffness of continuous fibre-reinforced semi-crystalline thermoplastics}

Due to their lightweight construction potential, continuous fibre-reinforced plastics (FRP) with a thermoset matrix are already widely used in aerospace, sports equipment technology, and the automotive industry. When considering certain aspects such as production rate, function integration through coupling to injection moulding processes [1], impact behaviour or recyclability, thermoplastic matrices offer advantages over thermoset matrices [2]. The applications in series production which have emerged from research projects, such as the development of a rear seat through-loading system [3], a battery carrier [4], or an engine mount [5], demonstrate the industry's interest in fibre-reinforced thermoplastics (FRTP). According to Kuhnel [6], both the classic laminate theory for stress analysis and physically based failure models such as the Failure Mode Concept (FMC) [7] for failure analysis can be applied equally to FRTP and duroplastic FRP when simulating failure behaviour. When performing such calculations, for example by using finite element programs, characteristic values for stiffness $\left(\mathrm{E}_{\|}{ }^{\mathrm{t}}, \mathrm{E}_{\|}{ }^{\mathrm{c}}\right.$, $\left.\mathrm{E}_{\perp}{ }^{\mathrm{t}}, \mathrm{E}_{\perp}{ }^{\mathrm{c}}, \mathrm{G}_{\perp \|}\right)$ and strength $\left(\mathrm{R}_{\|}{ }^{\mathrm{t}}, \mathrm{R}_{\|}{ }^{\mathrm{c}}, \mathrm{R}_{\perp}{ }^{\mathrm{t}}, \mathrm{R}_{\perp}{ }^{\mathrm{c}}, \mathrm{R}_{\perp \|}\right)$ depending on fibre orientation (parallel/transverse) and load direction (tensile/compressive), of the unidirectional (UD) layer are required. When working with semi-crystalline thermoplastic matrices such as polyamide 6 (PA6) or polypropylene (PP), a higher temperature dependence compared to thermosets has to be considered not only within processing temperatures such as during the automotive paint shop, investigated by Graetzl et al. [8], but also for

Digital Object Identifier: http://dx.doi.org/10.21935/tls.v4i1.143 www.lightweight-structures.de 
typical operating temperatures $\left(-30^{\circ} \mathrm{C}\right.$ to $\left.+85^{\circ} \mathrm{C}\right)$ for car body structures [9]. In particular, the matrixdominant properties of a UD layer, i.e. stiffness and strength perpendicular to the fibre orientation as well as shear properties, show a first loss in the range of the glass transition temperature $\mathrm{T}_{\mathrm{g}}$ due to relaxation (also termed $\beta$-relaxation) of the amorphous phase of the polymer and a second loss (also termed $\alpha$-relaxation), which occurs in the range below the crystalline melting temperature $\mathrm{T}_{\mathrm{m}}$ due to relaxation of the crystalline phase [10]. Ehrenstein et al. [11] specify further softening temperatures $T_{Y}$ due to $\mathrm{Y}$-relaxation and $T_{D}$ due to desorption of absorbed water. The different relaxation processes of a polymer are often indicated by Greek letters. An a-relaxation is the one that occurs at the highest temperature, followed by the $\beta$-relaxation at a lower temperature and so on. This nomenclature can raise concerns in that physically identical relaxation processes of two different polymer types do not always correspond in their designations [12]. Hufenbach et al. [10] compare different approaches, including a linear, a multilinear and a hyperbolic approach for the analytical description of this stepwise temperature-dependent decrease in stiffness and strength with increasing temperature. From this comparison, the hyperbolic model by Gibson [2] represented in equation (1) appears to be suitable for mapping the temperature dependence.

$\mathrm{P}(\mathrm{T})=\mathrm{P}_{1}-\frac{\left(\mathrm{P}_{1}-\mathrm{P}_{2}\right) \times\left[1+\tanh \left(\mathrm{k}_{1}\left(\mathrm{~T}-\mathrm{T}_{1}\right)\right)\right]}{2}-\frac{\left(\mathrm{P}_{2}-\mathrm{P}_{3}\right) \times\left[1+\tanh \left(\mathrm{k}_{2}\left(\mathrm{~T}-\mathrm{T}_{2}\right)\right)\right]}{2}$

Gibson et al. [2] introduce a total of seven parameters for modelling the hyperbolic function. The parameters $\mathrm{P}_{1-3}$ correspond to stiffness and strength values, respectively, with $\mathrm{P}_{1}$ being below the coldest investigated relaxation (considered as $\beta$-relaxation), $P_{2}$ between $\beta$ - and $\alpha$-relaxation and $P_{3}$ above $\alpha$-relaxation. The parameters $\mathrm{T}_{1-2}$ represent the position of the softening temperatures, with $\mathrm{T}_{1}$ approximating the $\beta$-relaxation temperature and $\mathrm{T}_{2}$ near the $\alpha$-relaxation temperature of the polymer matrix. $\mathrm{k}_{1}$ and $\mathrm{k}_{2}$ determine the gradient of the hyperbolic function in the relaxation range.

\subsection{Failure model for continuous fibre-reinforced thermoplastics}

According to Kuhnel [6], failure models based on the fracture mode, such as Puck's action plane strength criterion [13] or the FMC by Cuntze [14], are suitable for the strength analysis of FRTP with high fibre volume content and brittle fracture behaviour. Cuntze's criterion, which is used here, consists of the failure conditions FF1 and FF2 for fibre failure and the conditions IFF1, IFF2 and IFF3 for inter-fibre failure as shown in equations (2a) - (2e), which occur when acting stresses exceed the assigned strength $\left(\mathrm{R}_{\|}{ }^{\mathrm{t}}, \mathrm{R}_{\|}{ }^{\mathrm{c}}, \mathrm{R}_{\perp}{ }^{\mathrm{t}}, \mathrm{R}_{\perp}{ }^{\mathrm{c}}, \mathrm{R}_{\perp \|}\right)$. The ratios of acting stresses to the respective strength are referred to in the following as failure functions $F$, where the stresses are represented by the invariants $I_{1-5}$ (equations (3a) - (3e)). The failure conditions are supplemented by the free curve parameters $b_{\perp}^{\tau}$ and $b_{\perp \|}$, which can be determined from experimental data.

FF1:

$$
\mathrm{F}_{\|}{ }^{\sigma}=\frac{\mathrm{I}_{1}}{\mathrm{R}_{\|}{ }^{\mathrm{t}}}=1
$$

FF2:

$$
\mathrm{F}_{\|}{ }^{\tau}=\frac{-\mathrm{I}_{1}}{\mathrm{R}_{\|}{ }^{\mathrm{c}}}=1
$$

IFF1:

$$
\mathrm{F}_{\perp}{ }^{\sigma}=\frac{\mathrm{I}_{2}+\sqrt{\mathrm{I}_{4}}}{2 \mathrm{R}_{\perp}{ }^{\mathrm{t}}}=1
$$

IFF2:

$$
\mathrm{F}_{\perp \|}=\frac{\mathrm{I}_{3}^{3 / 2}}{\mathrm{R}_{\perp \|}{ }^{3}}+\mathrm{b}_{\perp \|} \frac{\mathrm{I}_{2} \mathrm{I}_{3}-\mathrm{I}_{5}}{\mathrm{R}_{\perp \|}{ }^{3}}=1
$$

IFF3:

$$
F_{\perp}^{\tau}=\left(b_{\perp}^{\tau}-1\right) \frac{I_{2}}{R_{\perp}{ }^{c}}+b_{\perp}^{\tau} \frac{\sqrt{I_{4}}}{R_{\perp}{ }^{c}}=1
$$


Cuntze [14] formulates the interaction of normal and shear stresses for the triaxial stress state $(\{\sigma\}=$ $\left.\left(\sigma_{1}, \sigma_{2}, \sigma_{3}, \tau_{23}, \tau_{13}, \tau_{12}\right)^{\mathrm{T}}\right)$ by using the following invariants $\mathrm{I}_{1-5}$.

$$
\begin{aligned}
& \mathrm{I}_{1}=\sigma_{1} \\
& \mathrm{I}_{2}=\sigma_{2}+\sigma_{3} \\
& \mathrm{I}_{3}=\tau_{31}{ }^{2}+\tau_{21}{ }^{2} \\
& \mathrm{I}_{4}=\left(\sigma_{2}-\sigma_{3}\right)^{2}+4 \tau_{23}{ }^{2} \\
& \mathrm{I}_{5}=\left(\sigma_{2}-\sigma_{3}\right)\left(\tau_{31}{ }^{2}-{\tau_{21}}^{2}\right)-4 \tau_{23} \tau_{31} \tau_{21}
\end{aligned}
$$

The resulting inverse reserve factor $1 / \mathrm{f}_{\text {res }}$ for the triaxial stress state, which predicts a first layer failure as soon as $1 / f_{\text {res }} \geq 1$, can be formed by connecting the failure functions of the five different failure mechanisms using a rounding exponent $\dot{m}[14]$ :

$$
\left(\frac{1}{\mathrm{f}_{\text {res }}}\right)^{\dot{\mathrm{m}}}=\left(\mathrm{F}_{\|}{ }^{\sigma}\right)^{\dot{\mathrm{m}}}+\left(\mathrm{F}_{\|}{ }^{\tau}\right)^{\dot{\mathrm{m}}}+\left(\mathrm{F}_{\perp}{ }^{\sigma}\right)^{\dot{\mathrm{m}}}+\left(\mathrm{F}_{\perp \|}\right)^{\dot{\mathrm{m}}}+\left(\mathrm{F}_{\perp}{ }^{\tau}\right)^{\dot{\mathrm{m}}}
$$

\subsection{Objective}

In this paper the selected hyperbolic approach according to Gibson et al. [2] for the analytical description of the temperature dependence of stiffness and strength is applied to continuous fibre-reinforced thermoplastics in the temperature range from $-20^{\circ} \mathrm{C}$ to $+80^{\circ} \mathrm{C}$ using the computer algebra system Wolfram Mathematica. For this purpose, the Gibson model is extended to an unlimited number of softening intervals in order to be able to map all softenings occurring in a semi-crystalline matrix. On the one hand, the agreement of the hyperbolic model with the test data is to be evaluated in order to determine for which of the investigated mechanical properties the model is applicable. On the other hand, proposals for the reduction of the experimental effort as well as the effort for the determination of optimal curve parameters $\left(\mathrm{P}_{1-3}, \mathrm{~T}_{1-2}, \mathrm{k}_{1-2}\right)$ of the hyperbolic parameter functions are to be developed. Subsequently, the determined temperature-dependent basic strengths are to be implemented into the FMC [14] in order to give an outlook on the application of the determined results in the strength analysis of continuous FRTP structures.

\section{Materials and methods}

\subsection{Test data and materials to be investigated}

The hyperbolic model according to Gibson et al. [2] is used to convert experimental data for strength and stiffness of continuous fibre-reinforced thermoplastics at different temperatures into a continuous function of temperature. The three Celanese Celstran ${ }^{\circledR}$ materials investigated are UD carbon or glass fibre-reinforced polyamide 6 with $60 \%$ fibre mass content (PA6-CF60, PA6-GF60) and UD glass fibrereinforced polypropylene with $70 \%$ fibre content (PP-GF70). For the strength and stiffness of the materials, results of tempered tests on flat samples are available, which were conducted in accordance with the test standards listed in Table 1. The tested materials are conditioned according to DIN EN ISO 1110. For the temperature range from $-20^{\circ} \mathrm{C}$ to $+80^{\circ} \mathrm{C}$, measured values of six to eight different temperatures are available for each material and parameter. 
Table 1: Underlying test standards for the mechanical properties of PA6-CF60, PA6-GF60 and PP-GF70 in the temperature range from $-20^{\circ} \mathrm{C}$ to $+80^{\circ} \mathrm{C}$

\begin{tabular}{ll}
\hline Test standard & Determined property \\
\hline DIN EN ISO 527-4 & $\mathrm{E}_{\|}{ }^{\mathrm{t}}, \mathrm{E}_{\perp}{ }^{\mathrm{t}}, \mathrm{R}_{\|}{ }^{\mathrm{t}}, \mathrm{R}_{\perp}{ }^{\mathrm{t}}$ \\
DIN EN ISO 14126 & $\mathrm{E}_{\|}{ }^{\mathrm{c}}, \mathrm{E}_{\perp}{ }^{\mathrm{c}}, \mathrm{R}_{\|}{ }^{ }, \mathrm{R}_{\perp}{ }^{\mathrm{c}}$ \\
DIN EN ISO 14129 & $\mathrm{G}_{\perp \|}$ \\
DIN 65148 & $\mathrm{R}_{\perp \|}$ \\
\hline
\end{tabular}

\subsection{Determination of softening temperatures}

The determination of the softening temperatures required to create the analytical models for the temperature-dependent mechanical properties corresponds to the procedure of dynamic mechanical analysis (DMA) according to Ehrenstein et al. [11] and the standards DIN EN ISO 6721-1 and -3. Table 2 shows the test conditions for the conducted DMA.

Table 2: DMA test conditions in accordance with DIN EN ISO 6721

\begin{tabular}{ll}
\hline Property & Value \\
\hline Temperature range & -50 to $+200{ }^{\circ} \mathrm{C}$ \\
Specimen & $35 \times 12 \times 2 \mathrm{~mm}$, waterjet cut \\
Heating rate & $3 \mathrm{~K} / \mathrm{min}$ \\
Material & PA6-CF60, PA6-GF60, PP-GF70 ( $0^{\circ}$ and $90^{\circ}$ direction) \\
Condition & dry $(<0.1 \%$ humidity); conditioned (approx. 0.4-2\% humidity) \\
Clamping & single cantilever \\
Precision scale & Precisa XR 205 SM-DR
\end{tabular}

When evaluating linearly recorded DMA diagrams, softening temperatures $\left(T_{\gamma}, T_{\beta}, T_{\alpha}, T_{D}\right)$ can be determined on the basis of the maxima of the loss modulus E", while the crystalline melting temperature $\mathrm{T}_{\mathrm{m}}$ is determined on the basis of the largest inclination of the storage modulus $\mathrm{E}^{\prime}$.

\subsection{Extension of the hyperbolic model, curve fitting of the hyperbolic function to experimental data and implementation of temperature dependence into a failure model}

In order to extend the number of considered softening phenomena from two ( $\alpha$ - and $\beta$-relaxation) to any number of phenomena ( $\alpha-, \beta-, y$-relaxation, desorption), the hyperbolic model of Eq. (1) is extended to $n$ softening transitions in Eq. (5):

$$
P(T)=P_{1}+\frac{1}{2} \sum_{i=1}^{n}\left(P_{i+1}-P_{i}\right)\left[1+\tanh \left(k_{i}\left(T-T_{i}\right)\right)\right]
$$

This type of series development can be applied here because $P_{i}$ represents a mechanical material property which can be measured at any temperature. With this extension, the temperature-dependent mechanical behaviour of FRTP can hypothetically be modelled in any range from absolute freezing point to decomposition, if enough experimental data are available. For such a characterisation, the softening temperatures in the investigated temperature range must first be determined, e.g. by means of a DMA as described in 2.2. Subsequently, the amount $n$ and temperatures $T_{I}\left(T_{I} \in T_{\gamma}, T_{\beta}, T_{\alpha}, T_{D}\right)$ of the 
softenings to be modelled for the range of interest can be determined and the extended hyperbolic model (Eq. (5)) can then be reduced again to the required number of parameters. By fitting the model to test values from mechanical testing (cf. Table 1) at different temperatures with fixed intervals of $10^{\circ} \mathrm{C}$ or $20^{\circ} \mathrm{C}$, continuous curves of mechanical properties as a function of temperature are generated. For such curve fitting, scripts are created using Wolfram Mathematica, which optimise the free parameters $\left(\mathrm{P}_{\mathrm{j}}, \mathrm{T}_{\mathrm{i}}\right.$ and $\left.\mathrm{k}_{\mathrm{i}}\right)$ by minimising the mean square error between curve and test values. This curve fitting is performed for all ten mechanical properties $\left(\mathrm{E}_{\|}{ }^{\mathrm{t}}, \mathrm{E}_{\|}{ }^{\mathrm{c}}, \mathrm{E}_{\perp}{ }^{\mathrm{t}}, \mathrm{E}_{\perp}{ }^{\mathrm{c}}, \mathrm{G}_{\perp \|}, \mathrm{R}_{\|}{ }^{\mathrm{t}}, \mathrm{R}_{\|}{ }^{\mathrm{c}}, \mathrm{R}_{\perp}{ }^{\mathrm{t}}, \mathrm{R}_{\perp}{ }^{\mathrm{c}}, \mathrm{R}_{\perp \|}\right)$ per investigated material (PA6-GF60, PA6-CF60, PP-GF70). In order to obtain physically justifiable results for the parameters during curve fitting, the following limits are defined for the free parameters $\mathrm{k}_{\mathrm{i}}, \mathrm{T}_{\mathrm{i}}$ and $P_{\mathrm{j}}$ :

$>0.001<\mathrm{k}_{\mathrm{i}}<0.1 ; \mathrm{i}=1 \ldots \mathrm{n}$

$>\left(\mathrm{T}_{1}-20^{\circ} \mathrm{C}\right)<\mathrm{T}_{\mathrm{i}}<\left(\mathrm{T}_{1}+20^{\circ} \mathrm{C}\right) ; \mathrm{i}=1 \ldots \mathrm{n}$;

$T_{I} \in T_{\gamma}, T_{\beta}, T_{\alpha}, T_{D}$ (from DMA measurements)

$>\mathrm{P}_{\mathrm{n}+1}=0 \mathrm{MPa}<\mathrm{P}_{\mathrm{n}}<\mathrm{P}_{\mathrm{n}-1}<\ldots<\mathrm{P}_{2}<\mathrm{P}_{1}$

The specified inequality conditions as search limits for the parameters $P_{j}(j \in 1, \ldots, n+1)$ of the hyperbolic function result from the fact that all investigated stiffnesses and strengths decrease with increasing temperature. Based on the assumption that all mechanical characteristic values of the FRTP approach zero at the latest with increasing temperature due to decomposition of the individual components, the search limit $P_{n+1}=0 \mathrm{MPa}$ is also specified.

In addition to the previously described first variant (V1) of a curve fitting to all given test values by optimising every parameter $\left(\mathrm{k}_{\mathrm{i}}, \mathrm{T}_{\mathrm{i}}\right.$ and $\left.\mathrm{P}_{\mathrm{j}}\right)$ for each stiffness or strength of a material, two further variants of curve fitting are performed in order to investigate possibilities for reducing the number of parameters, the effort for parameter fitting as well as for mechanical testing in future material analyses. The fitting variant $2(\mathrm{~V} 2)$ aims to reduce the number of curve parameters $k_{i}$ and $T_{i}$ per material by averaging each of them $\left(\mathrm{k}_{1} \ldots \mathrm{k}_{\mathrm{n}}, \mathrm{T}_{1} \ldots \mathrm{T}_{\mathrm{n}}\right)$ over all mechanical parameters $\left(\mathrm{E}_{\|}{ }^{\mathrm{t}}, \mathrm{E}_{\|}{ }^{\mathrm{c}}, \mathrm{E}_{\perp}{ }^{\mathrm{t}}, \mathrm{E}_{\perp}{ }^{\mathrm{c}}, \mathrm{G}_{\perp \|}, \mathrm{R}_{\|}{ }^{\mathrm{t}}, \mathrm{R}_{\|}{ }^{\mathrm{c}}, \mathrm{R}_{\perp}{ }^{\mathrm{t}}, \mathrm{R}_{\perp}{ }^{\mathrm{c}}, \mathrm{R}_{\perp \|}\right)$. Thus, only the optimum parameters $P_{j}$ of each material property have to be determined. Fitting variant 3 (V3), on the other hand, provides a parameter adjustment for every single parameter as in V1, but aims to reduce the testing effort. The number of tests to be performed is reduced by not performing mechanical measurements at fixed intervals of $10{ }^{\circ} \mathrm{C}$ or $20{ }^{\circ} \mathrm{C}$, but only at relevant measuring temperatures $\left(\mathrm{MT}_{\mathrm{i}}\right)$. The selection of these relevant measuring temperatures is based on the softening temperatures $T_{I} \in T_{\gamma}, T_{\beta}, T_{\alpha}, T_{D}$ determined by the DMA and the minimum $T_{\min }$ and maximum $T_{\max }$ of the operating temperature range:

$$
\begin{aligned}
& >\mathrm{MT}_{1}=\mathrm{T}_{\min } \\
& >\mathrm{MT}_{\mathrm{i}}=\mathrm{T}_{\mathrm{I}} \pm 10^{\circ} \mathrm{C} ; \mathrm{T}_{\mathrm{I}} \in \mathrm{T}_{\mathrm{V}}, \mathrm{T}_{\beta}, \mathrm{T}_{\alpha}, \mathrm{T}_{\mathrm{D}} ; \mathrm{i}=2 \ldots \mathrm{n}-1 \\
& >\mathrm{MT} \mathrm{T}_{\mathrm{n}}=\mathrm{T}_{\max }
\end{aligned}
$$

The quality of the curve fitting of the three variants is determined using the root mean square errors (RMSE) between the adapted curve and the test values. In order to be able to compare the three fitting variants with each other across materials and mechanical properties, the RMSE is normalised to the mean value of the minimum and maximum of the test values of a measured strength or stiffness (nRMSE).

To investigate the applicability of the basic mechanical properties as a hyperbolic function for the strength analysis of unidirectional fibre-reinforced thermoplastics, the temperature dependence is implemented into the FMC [14] by replacing the constant strength values by the determined temperature-dependent strengths $\left(\mathrm{R}_{\|}{ }^{t}(T), \mathrm{R}_{\|}{ }^{\mathrm{c}}(\mathrm{T}), \mathrm{R}_{\perp}{ }^{\mathrm{t}}(T), \mathrm{R}_{\perp}{ }^{\mathrm{c}}(\mathrm{T}), \mathrm{R}_{\perp \|}(\mathrm{T})\right)$. For this purpose equations (2) to (4) of the FMC are programmed in Wolfram Mathematica and extended by the developed hyperbolic functions for the temperature-dependent strengths according to equation (5). For the investigated materials, the $\sigma_{2}-\tau_{21}$ failure curves as well as $\sigma_{1}-\sigma_{2}-\tau_{21}$ failure bodies can be generated with this script for arbitrary temperatures in the examined range from $-20^{\circ} \mathrm{C}$ to $+80^{\circ} \mathrm{C}$. Furthermore, the $\sigma_{2}$ $\tau_{21}$-failure curve as a function of temperature can be illustrated as a $\sigma_{2}-\mathrm{T}-\tau_{21}$ failure surface. 


\section{$3 \quad$ Results}

\subsection{Softening temperatures from Dynamic Mechanical Analysis}

Diagrams for the determination of softening temperatures were recorded for all three materials, both under bending load in the fibre direction and transverse to the fibre direction. By analysing the diagrams, the following relaxation and melting temperatures were determined.

Table 3: Softening temperatures determined from DMA diagrams

\begin{tabular}{lllllll}
\hline Material & Fibre orientation & $\mathbf{T}_{\mathbf{V}} /{ }^{\circ} \mathbf{C}$ & $\mathbf{T}_{\boldsymbol{\beta}} /{ }^{\circ} \mathbf{C}$ & $\mathbf{T}_{\boldsymbol{\alpha}} /{ }^{\circ} \mathbf{C}$ & $\mathbf{T}_{\mathbf{D}} /{ }^{\circ} \mathbf{C}$ & $\mathbf{T}_{\mathbf{m}} /{ }^{\circ} \mathbf{C}$ \\
\hline PA6-CF60 & $90^{\circ}$ & $-140^{2}$ & $-70^{2}$ & 22 & 91 & $220^{3}$ \\
& $0^{\circ}$ & $-140^{2}$ & $-70^{2}$ & 31 & 94 & $220^{3}$ \\
PA6-GF60 & $90^{\circ}$ & $-140^{2}$ & $-70^{2}$ & 11 & 94 & $220^{3}$ \\
& $0^{\circ}$ & $-140^{2}$ & $-70^{2}$ & 20 & 90 & $220^{3}$ \\
PP-GF70 & $90^{\circ}$ & 1 & 3 & 70 & 1 & 155 \\
& $0^{\circ}$ & 1 & 9 & 98 & 1 & 155 \\
\hline
\end{tabular}

${ }^{1}$ no softening effects recognisable
${ }^{2}$ estimated from DMA diagrams in literature [11]
${ }^{3}$ taken from data sheet [15]

For PA6-CF60 and PA6-GF60, $\gamma$ - and $\beta$-relaxation temperature as well as $T_{m}$ are below or above the measuring scope and can therefore not be measured. They are therefore estimated from DMA diagrams measured by Ehrenstein et al. [11] or taken from data sheets. For the PA6 matrix composites, a further peak at the desorption temperature $\mathrm{TD}_{\mathrm{D}}\left(90^{\circ} \mathrm{C}\right.$ to $\left.100^{\circ} \mathrm{C}\right)$ can be detected in addition to the peaks at relaxation and melting temperatures. Throughout desorption, the water previously absorbed during conditioning exits the matrix due to the transition into the gas phase, leaving small voids and increasing the residual stresses in the composite, which leads to a change in strength and stiffness [11]. In contrast, DMA diagrams of dried PA6 samples and samples with PP matrix do not show significant peaks and thus no changes in mechanical properties due to desorption. The relaxation temperatures $T_{\alpha}$ and $T_{\beta}$ of specimens with loads in fibre direction are shifted by $6^{\circ} \mathrm{C}$ to $28^{\circ} \mathrm{C}$ to higher temperatures for all three materials compared to the tests transverse to the fibre direction. Figure 1 shows the shift in the loss modulus E" for PP-GF70 comparing specimens with $0^{\circ}$ and $90^{\circ}$ fibre orientation. Ehrenstein explains this phenomenon by the different temperature distribution during the test, which results from different fibre orientations [11]. Accordingly, $0^{\circ}$ specimens dissipate heat faster to the clamping during the bending test than the $90^{\circ}$ specimens resulting in the actual specimen temperature of the $0^{\circ}$ specimens being below the recorded specimen temperature. Thus, the softening temperatures seem to be higher for $0^{\circ}$ specimens than for $90^{\circ}$ specimens. 


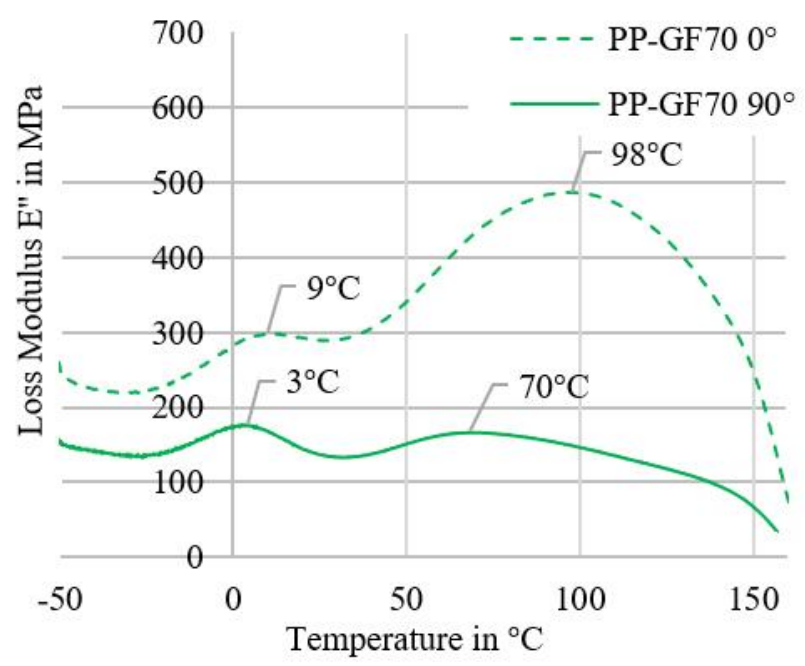

Figure 1: DMA diagram with loss moduli for PP-GF70 with $0^{\circ}$ and $90^{\circ}$ fibre orientation

Furthermore, due to the higher thermal conductivity of carbon fibres compared to glass fibres, the softening temperatures of PA6-CF60 samples appear higher than those of PA6-GF60 samples, although the same matrix is used. Consequently, it is assumed that the softening temperatures for PA6CF60 and PA6-GF60 are identical for $90^{\circ}$ and $0^{\circ}$ specimens, although the DMA diagrams show differences. Therefore, the softening temperatures $T_{1}$ in Table 4 are used in order to define the fitting limits for the parameters $T_{i}$ as well as the temperatures $M T_{i}$ for measuring the support values of the hyperbolic model for the mechanical properties of PA6-GF60, PA6-CF60 and PP-GF70.

Table 4: Softening temperatures $T_{1}$ used for modelling the temperature-dependent mechanical properties

\begin{tabular}{llllll}
\hline Material & $\mathbf{T}_{5}=\mathbf{T}_{\mathbf{V}} /{ }^{\circ} \mathbf{C}$ & $\mathbf{T}_{\mathbf{4}}=\mathbf{T}_{\boldsymbol{\beta}} /{ }^{\circ} \mathbf{C}$ & $\mathbf{T}_{\mathbf{3}}=\mathbf{T}_{\boldsymbol{\alpha}} /{ }^{\circ} \mathbf{C}$ & $\mathbf{T}_{\mathbf{2}}=\mathbf{T}_{\mathbf{D}} /{ }^{\circ} \mathbf{C}$ & $\mathbf{T}_{\mathbf{1}}=\mathbf{T}_{\mathbf{m}} /{ }^{\circ} \mathbf{C}$ \\
\hline PA6-CF60 & $-140^{2}$ & $-70^{2}$ & 11 & 94 & $220^{3}$ \\
PA6-GF60 & $-140^{2}$ & $-70^{2}$ & 11 & 94 & $220^{3}$ \\
PP-GF70 & 1 & 3 & 70 & 1 & 155 \\
\hline
\end{tabular}

${ }^{1}$ no softening effects recognisable

2 estimated from DMA diagrams in literature [11]

${ }^{3}$ taken from data sheet [15]

\subsection{Application of a hyperbolic model to the temperature dependence of FRTPs' mechanical properties}

In the following, the hyperbolic temperature curves for the investigated mechanical properties of PA6CF60, PA6-GF60 and PP-GF70, which were generated using Wolfram Mathematica scripts according to the fitting variants $\mathrm{V} 1, \mathrm{~V} 2$ and $\mathrm{V} 3$, are discussed with regard to the applicability of the hyperbolic model and the fitting methods used. Only few of the 90 determined hyperbolic temperature curves (3 materials $\times 10$ mechanical properties $\times 3$ fitting variants) are presented in this chapter to visualise the relevant conclusions.

Applicability of the hyperbolic model to FRTPs' anisotropic strengths and stiffnesses

Studying the fibre-dominant stiffness characteristics $\mathrm{E}_{\|}{ }^{\mathrm{t}}$ and $\mathrm{E}_{\|}{ }^{\mathrm{c}}$ (see Figure 2) of the investigated FRTPs, only negligible temperature dependencies can be determined. The application of the hyperbolic model for fibre-parallel stiffness is therefore not considered necessary. 

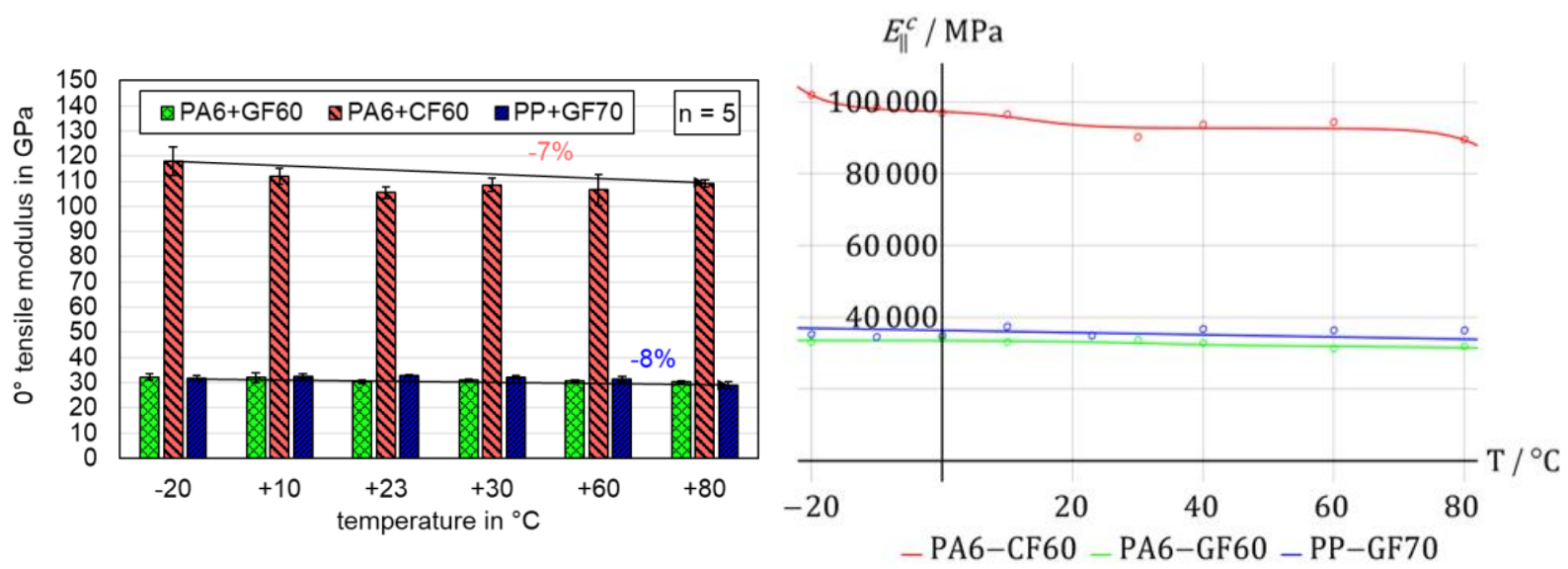

Figure 2: Temperature-dependent tensile $E_{\|}{ }^{t}$ and compressive stiffness $E_{\|}{ }^{c}(T)$ in fibre direction of PA6-CF60, PA6-GF60 and PP-GF70 as hyperbolic function, fitted (V1) to the test values

The functions of fibre-parallel tensile strength $\mathrm{R}_{\|}{ }^{\mathrm{t}}$ for PA6-CF60, PA6-GF60 and PP-GF70, on the other hand, show an average loss of $26.4 \%$ within the temperature range from $-20^{\circ} \mathrm{C}$ to $+80^{\circ} \mathrm{C}$, see Figure 3. An explanation for this mechanical loss of tensile strength with increasing temperature is the decreasing fibre-matrix adhesion as well as the reduced force transmission capacity between matrix and fibres due to the decreasing matrix stiffness. Consequently, weaker fibres due to production variations can be compensated less effectively by stronger surrounding fibres. Subsequently, the application of the hyperbolic model to describe the temperature dependence of $\mathrm{R}_{\|}{ }^{\mathrm{t}}$ is considered useful.

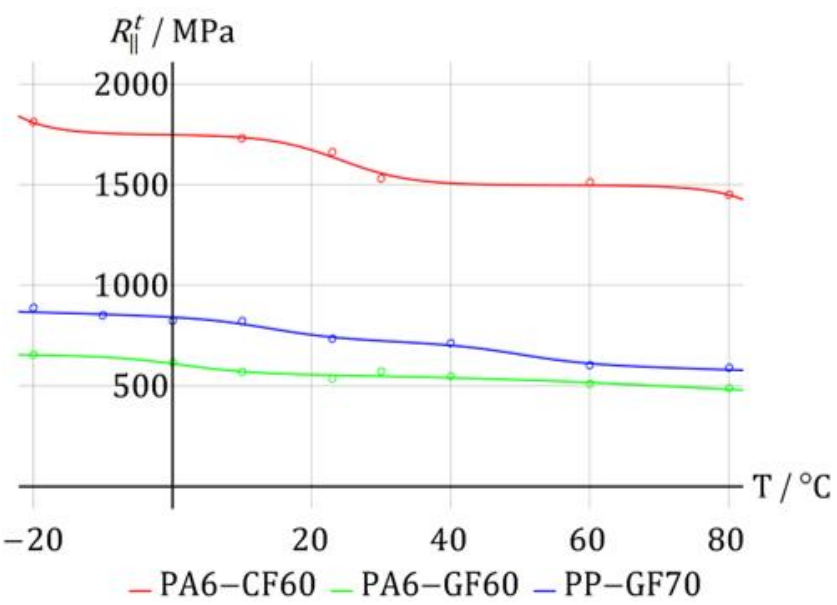

Figure 3: Temperature-dependent tensile strength $R_{\|}{ }^{t}(T)$ in fibre direction of PA6-CF60, PA6-GF60 and PP-GF70 as hyperbolic function, fitted to the test values according to fitting variant $V 1$

The fibre-parallel compressive strength $\mathrm{R}_{\|}{ }^{\mathrm{c}}$ exhibits a more distinct temperature dependence, as do all the matrix-dominant properties investigated $\left(\mathrm{E}_{\perp}{ }^{\mathrm{t}}, \mathrm{E}_{\perp}{ }^{\mathrm{c}}, \mathrm{G}_{\perp \|}, \mathrm{R}_{\perp}{ }^{\mathrm{t}}, \mathrm{R}_{\perp}{ }^{\mathrm{c}}, \mathrm{R}_{\perp \|}\right)$. Figure 4 shows the temperature-dependent tensile strength $\mathrm{R}_{\perp}{ }^{\mathrm{t}}(\mathrm{T})$ of PA6-CF60, PA6-GF60 and PP-GF70 as one reasonable application of the hyperbolic model. 


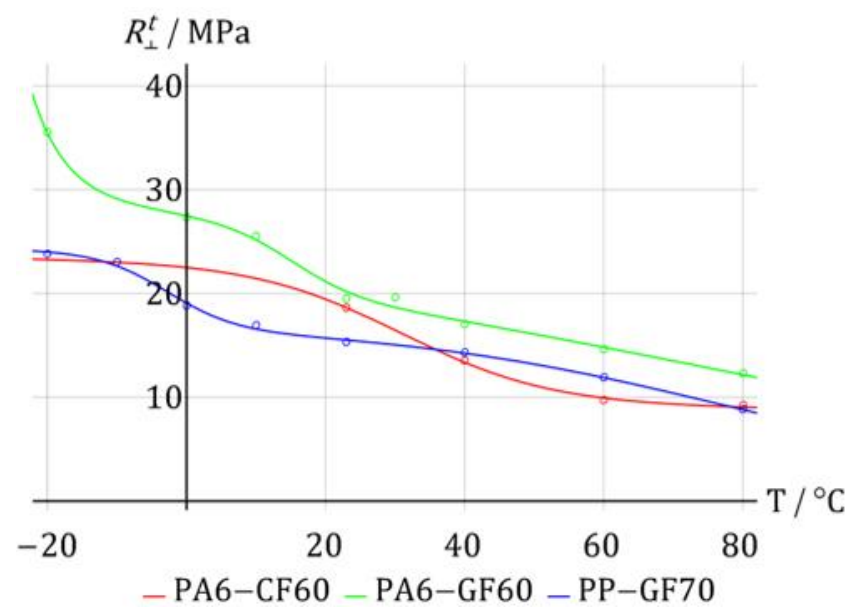

Figure 4: Temperature-dependent tensile strength $R_{\perp}{ }^{t}(T)$ transverse to the fibre direction of PA6CF60, PA6-GF60 and PP-GF70 as hyperbolic function, fitted to the test values according to fitting variant $V 1$

\section{Quality of fitting variants V1, V2 and V3}

In order to compare the quality of curve fitting variants $\mathrm{V} 1$, V2 and V3, Table 5 presents the nRMSE of each hyperbolic function generated, fitted to the strength and stiffness values measured at various temperatures. The deviation between model and test values when using fitting variant $\mathrm{V} 1$ with a full test data set of up to eight measuring temperatures, averaged over all properties and materials, is $1.9 \%$ with a maximum deviation of $\mathrm{nRMSE}=7.51 \%$ for $\mathrm{R}_{\|}{ }^{\mathrm{c}}$ (PP-GF70). From this, it can be concluded that the modelling of the temperature dependence by the hyperbolic model fitted with a Mathematica script according to $\mathrm{V} 1$ agrees very precisely to the actual material behaviour.

Table 5: nRMSE calculated from the deviations between fitted hyperbolic models and experimental values for strength and stiffness of PA6-CF60, PA6-GF60 and PP-GF70

\begin{tabular}{|c|c|c|c|c|c|c|c|c|c|c|c|c|}
\hline \multirow{2}{*}{$\begin{array}{l}\text { Fitting } \\
\text { variant }\end{array}$} & \multirow[t]{2}{*}{ Material } & \multicolumn{10}{|c|}{ normalised Root Mean Square Error nRMSE / \% } & \multirow{2}{*}{$\begin{array}{l}\text { Averaged } \\
\text { nRMSE }\end{array}$} \\
\hline & & $\mathbf{R}_{\|}{ }^{\mathrm{t}}$ & $\mathbf{R}_{\|}{ }^{\mathbf{c}}$ & $\mathbf{R}_{\perp}{ }^{\mathrm{t}}$ & $\mathbf{R}_{\perp}{ }^{\mathbf{c}}$ & $\mathbf{R}_{\perp \|}$ & $\mathbf{E}_{\|}{ }^{\mathrm{t}}$ & $\mathbf{E}_{\|}{ }^{\mathbf{c}}$ & $E_{\perp}{ }^{t}$ & $\mathbf{E}_{\perp}{ }^{\mathbf{c}}$ & $\mathbf{G}_{\perp \|}$ & \\
\hline \multirow[t]{3}{*}{ V1 } & PA6-CF60 & 0.95 & 0.37 & 1.11 & 0.00 & 3.15 & 1.20 & 1.27 & 0.00 & 1.28 & 3.02 & \\
\hline & PA6-GF60 & 1.91 & 2.05 & 1.90 & 1.18 & 2.06 & 1.55 & 1.12 & 0.55 & 1.08 & 0.00 & \multirow{2}{*}{$1.9 \%$} \\
\hline & PP-GF70 & 1.77 & 7.51 & 1.35 & 4.20 & 0.59 & 1.75 & 4.75 & 4.19 & 1.66 & 3.88 & \\
\hline \multirow[t]{3}{*}{ V2 } & PA6-CF60 & 13.27 & 14.46 & 31.51 & 46.70 & 33.78 & 1.50 & 288.6 & 35.86 & 27.19 & 25.47 & \\
\hline & PA6-GF60 & 56.79 & 21.47 & 23.91 & 36.28 & 98.46 & 12.16 & 2.10 & 25.72 & 19.39 & 19.69 & \multirow{2}{*}{9} \\
\hline & PP-GF70 & 87.90 & 36.95 & 19.13 & 39.93 & 28.97 & 44.80 & 99.54 & 42.70 & 51.00 & 41.30 & \\
\hline \multirow[t]{3}{*}{ V3 } & PA6-CF60 & 2.21 & 2.25 & 5.16 & 4.82 & 5.31 & 1.21 & 2.56 & 0.56 & 3.73 & 3.78 & \multirow{3}{*}{$4.6 \%$} \\
\hline & PA6-GF60 & 3.47 & 6.60 & 3.89 & 2.26 & 5.48 & 1.47 & 3.00 & 2.43 & 2.22 & 6.86 & \\
\hline & PP-GF70 & 2.72 & 13.74 & 5.94 & 8.98 & 2.42 & 1.77 & 4.80 & 12.22 & 7.52 & 8.54 & \\
\hline
\end{tabular}

The averaged deviation of $44.2 \%$ with a maximum nRMSE of $288.6 \%$ for the models fitted according to fitting variant V2 obviously suggests that the number of model parameters per material cannot be reduced by averaging each $P_{j}$ and $k_{i}$ over all strengths and stiffnesses. Fitting variant $V 3$, which aims to reduce the experimental effort by selecting only relevant measuring temperatures $M \mathrm{M}_{\mathrm{I}}$ according to the softening ranges of the semi-crystalline matrices, results in a mean deviation of $n R M S E(V 3)=4.6 \%$ averaged over all properties and materials and a maximum of $13.74 \%$ for $R_{\|}{ }^{c}(T)$ of PP-GF70. Showing good agreement between the measured values and the hyperbolic model across all investigated material properties and materials, this method of selecting only the essential measuring temperatures 
for mechanical testing promises an appropriate possibility for minimising cost and time for determining a predictive model of temperature-dependent strengths and stiffnesses. Assuming that for the characterisation of one material in the temperature range from $-20{ }^{\circ} \mathrm{C}$ to $+80{ }^{\circ} \mathrm{C}$ according to $\mathrm{V} 1$ mechanical tests for ten material properties $\left(\mathrm{E}_{\|}{ }^{\mathrm{t}}, \mathrm{E}_{\|}{ }^{\mathrm{c}}, \mathrm{E}_{\perp}{ }^{\mathrm{t}}, \mathrm{E}_{\perp}{ }^{\mathrm{c}}, \mathrm{G}_{\perp \|}, \mathrm{R}_{\|}{ }^{\mathrm{t}}, \mathrm{R}_{\|}{ }^{\mathrm{c}}, \mathrm{R}_{\perp}{ }^{\mathrm{t}}, \mathrm{R}_{\perp}{ }^{\mathrm{c}}, \mathrm{R}_{\perp \|}\right)$ must be carried out at eight different temperatures with intervals of approx. $15^{\circ} \mathrm{C}$ and five repetitions per test, a total test scope of 400 tests results. In comparison, according to fitting variant $\mathrm{V} 3$, for the same properties in the same temperature range and the same number of repetitions, only measurements at four different temperatures $\left(\mathrm{MT}_{\mathrm{i}}:-20^{\circ} \mathrm{C}, 0^{\circ} \mathrm{C}, 20^{\circ} \mathrm{C}, 80^{\circ} \mathrm{C}\right)$ for composites with a PA6 matrix, or five different temperatures $\left(\mathrm{MT}_{\mathrm{i}:}-20^{\circ} \mathrm{C},-10^{\circ} \mathrm{C}, 10^{\circ} \mathrm{C}, 60^{\circ} \mathrm{C}, 80^{\circ} \mathrm{C}\right)$ for composites with a PP matrix, and therefore only 200 or 250 tests, respectively, are necessary, instead of 400 . To compare the fitting variants, Figure 5 shows the temperature-dependent transverse compressive strength $R_{\perp}{ }^{c}(T)$ of PA6-GF60, fitted according to $\mathrm{V} 1, \mathrm{~V} 2$ and $\mathrm{V} 3$.

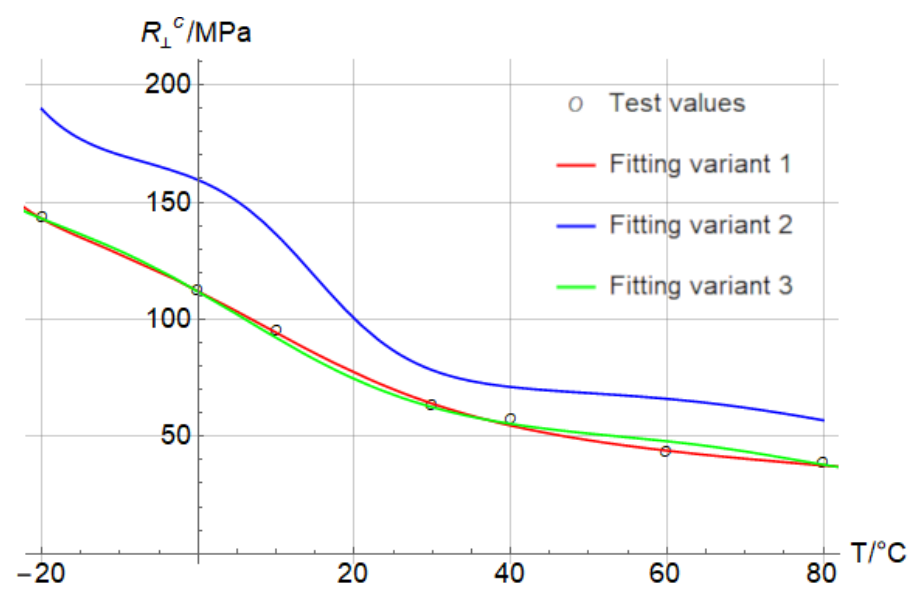

Figure 5: Temperature-dependent compressive strength $R_{\perp}{ }^{c}(T)$ transverse to the fibre direction of PA6GF60 as hyperbolic function, fitted to test values according to the fitting variants V1, V2 and V3

The deviations between model and experimental values are $\mathrm{nRMSE}(\mathrm{V} 1)=1.2 \%$, $\mathrm{nRMSE}(\mathrm{V} 2)=36.3 \%$ and $\mathrm{nRMSE}(\mathrm{V} 3)=2.3 \%$. For further improvement of the fitting method V3 with a reduced data set, the influence of the distance between softening temperatures $T_{1}$, measured by DMA, and the relevant measuring temperatures $\mathrm{MT}_{i}$ for mechanical testing on the prediction accuracy should be investigated in further studies.

\subsection{Implementation of the modelled temperature-dependent basic strengths into a failure model for continuous fibre-reinforced plastics}

By implementing the determined hyperbolic functions for the strengths $\left(\mathrm{R}_{\|}{ }^{\mathrm{t}}, \mathrm{R}_{\|}{ }^{\mathrm{c}}, \mathrm{R}_{\perp}{ }^{\mathrm{t}}, \mathrm{R}_{\perp}{ }^{\mathrm{c}}, \mathrm{R}_{\perp \|}\right)$ of PA6CF60, PA6-GF60 and PP-GF70 into Cuntze's FMC [14], the failure conditions can be illustrated as curves or surfaces for any temperature in the range from $-20^{\circ} \mathrm{C}$ to $+80^{\circ} \mathrm{C}$. The free parameters $\mathrm{b}_{\perp \|}$, $\mathrm{b}_{\perp}^{\tau}$ and $\dot{\mathrm{m}}$ which are required in the $\mathrm{FMC}$ are derived from tests with combined axial (tensile or compressive) and torsional loads on $90^{\circ}$ tape-wound tube specimens at room temperature (see Figure 6) $[1,16]$. 


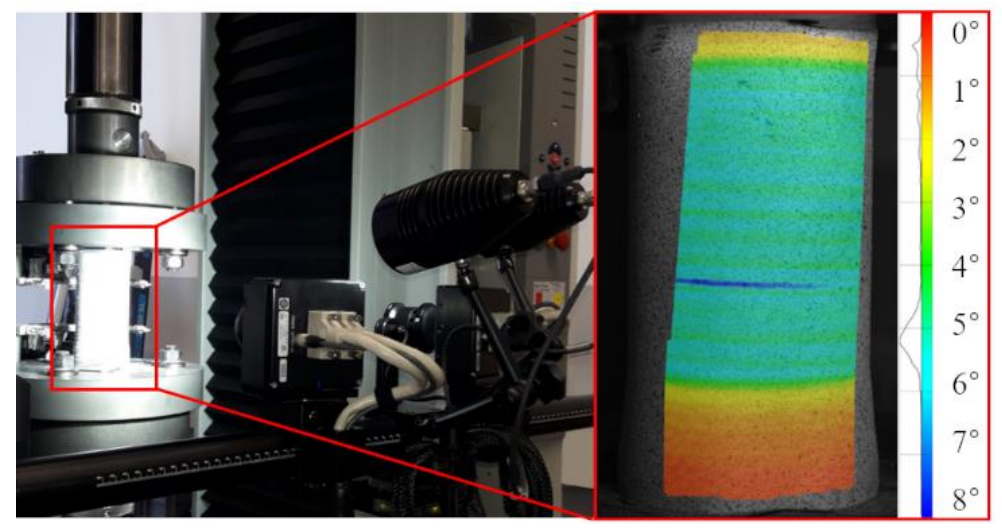

Figure 6: ZWICK universal testing machine Z250 with tape-wound tube specimen and optical 3D deformation analysis system ARAMIS for the measurement of the torsion angle during torsion testing

The results for the free parameters $b_{\perp \|}, b_{\perp}^{\tau}$ and $\dot{m}$, which were determined by fitting the biaxial failure curves to the test values, are shown in Table 6.

Table 6: $\quad$ Free parameters used in the failure conditions according to the FMC [14]

\begin{tabular}{llll}
\hline Material & bbsp $\equiv \mathbf{b}_{\perp \|}$ & bstau $\equiv \mathbf{b}_{\perp}^{\mathbf{\tau}}$ & mdot $\equiv \dot{\mathbf{m}}$ \\
\hline PA6-CF60 & 0.85 & 1.0 & 1.54 \\
PA6-GF60 & 0.32 & 1.0 & 1.84 \\
PP-GF70 & 0.95 & 1.0 & 1.67 \\
\hline
\end{tabular}

Figure 7 shows the $\sigma_{2}-\tau_{21}$ failure curves for PA6-GF60 at $-20^{\circ} \mathrm{C},+23^{\circ} \mathrm{C}$ and $+80^{\circ} \mathrm{C}$ as examples of the hyperbolic temperature dependency of the strengths implemented into the failure mode-related failure conditions. In addition to the failure curves, the diagram includes the strength values $R_{\perp}{ }^{\mathrm{c}}, \mathrm{R}_{\perp}{ }^{\mathrm{t}}$ and $\mathrm{R}_{\perp \|}$ of tested flat specimens as well as failure stress values of biaxial $\sigma_{2}-\tau_{21}$ tests at room temperature with wound tube specimens.

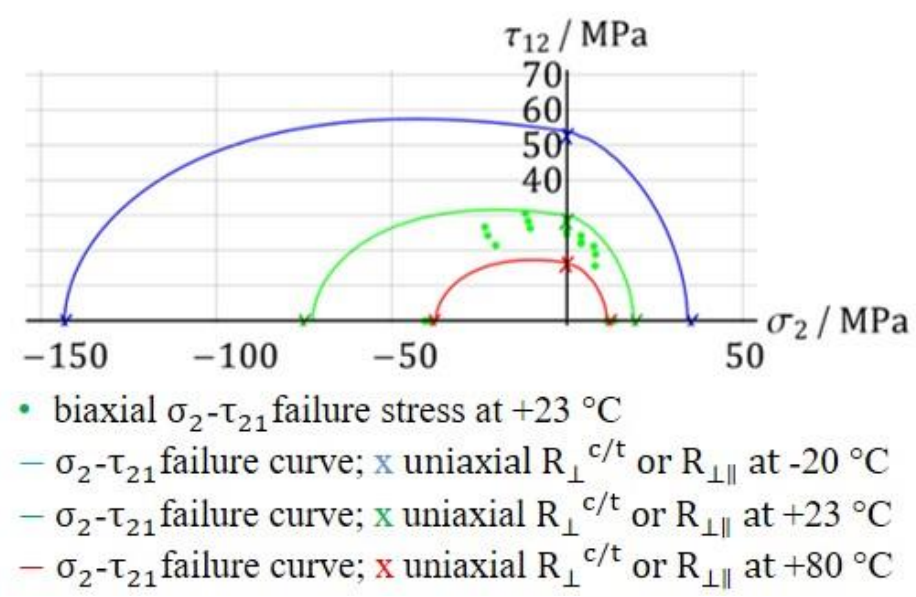

Figure 7: $\sigma_{2}-\tau_{21}$ failure curves according to Cuntze with implemented temperature-dependent basic strengths according to Gibson for PA6-GF60 at $-20^{\circ} \mathrm{C},+23{ }^{\circ} \mathrm{C}$ and $+80^{\circ} \mathrm{C}$

When comparing the test values from biaxial tests on tube specimens with the failure curve for room temperature generated from the test values of flat specimens, it is evident that the failure curve predicts greater failure stresses than the biaxial tests, particularly in the compression range of the $\sigma_{2}-\tau_{21}$ diagram. Possible reasons for this deviation are influences of the specimen geometry and the manufacturing process. As a further example for the visualisation of the failure model with implemented temperature- 
dependent strengths, Figure 8 shows the $\sigma_{2}-\sigma_{1}-\tau_{21}$ failure body of PA6-GF60, which can be plotted at any temperature in the investigated range using the Mathematica script, and is presented here for $-20^{\circ} \mathrm{C},+23^{\circ} \mathrm{C}$ and $+80^{\circ} \mathrm{C}$.

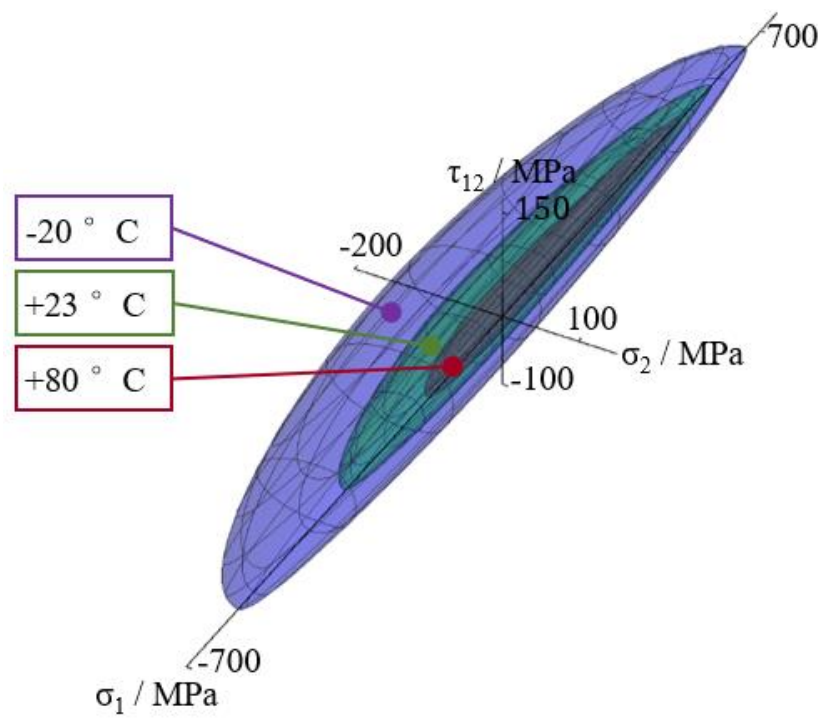

Figure 8: $\sigma_{1}-\sigma_{2}-\tau_{21}$ failure body according to Cuntze's FMC [14] with implemented temperaturedependent basic strengths for PA6-GF60 at $-20{ }^{\circ} \mathrm{C},+23^{\circ} \mathrm{C}$ and $+80{ }^{\circ} \mathrm{C}$

Moreover, Figure 9 illustrates the highly non-linear temperature-dependent failure behaviour of the investigated FRTPs as an extension of the usual $\sigma_{2}-\tau_{21}$ failure curves by temperature as the third dimension, resulting in $\sigma_{2}-\mathrm{T}-\tau_{21}$ failure surfaces. With the presentation of different failure curves and surfaces in Figures 7-9, the technical feasibility of a script-based implementation of Gibson's [2] hyperbolic approach for temperature dependence into Cuntze's [14] Failure Mode Concept for FRTPS is illustrated.
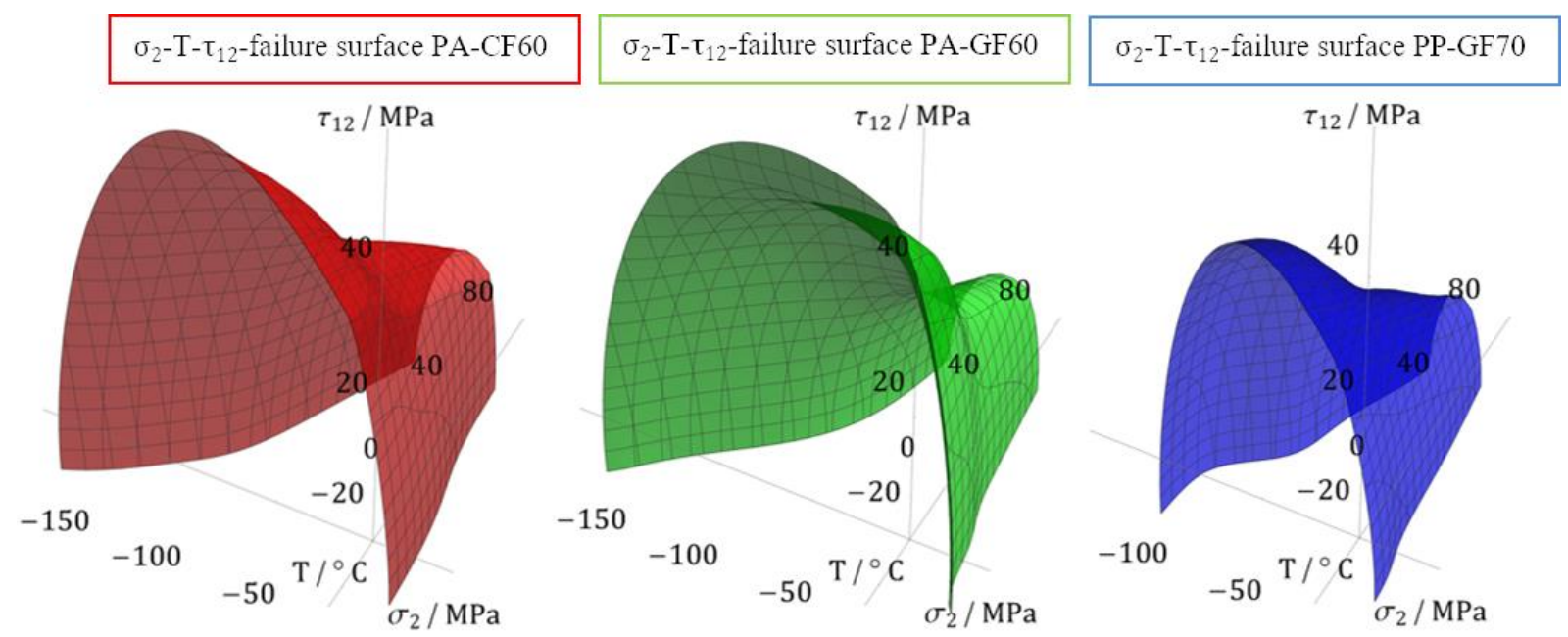

Figure 9: $\sigma_{2}-T-\tau_{21}$ failure surfaces for PA6-CF60, PA6-GF60 and PP-GF70 in the range from $-20{ }^{\circ} \mathrm{C}$ to $+80{ }^{\circ} \mathrm{C}$

Then, physical aspects of feasibility and applicability have to be discussed. One fundamental assumption of Cuntze for the application of the FMC is the brittle failure behaviour of the investigated composite, which can be analysed from fracture images. As the fracture images in Table 7 from compression tests demonstrate, the fulfilment of this assumption must be critically examined, especially when the matrix-dominant directions of the FRTPs are loaded at elevated temperatures. At room 
temperature, all three materials show the assumed fracture pattern for transverse pressure failure due to shearing in the fracture plane. At $80^{\circ} \mathrm{C}$, however, the fracture behaviour differs for each material. While the failure pattern in PA6-CF60 and PA6-GF60 can still be classified as brittle fracture, PP-GF70 shows mixed failure of bulging and shear failure.

Table 7: Microscopic images of specimens from compression tests to determine the transverse compressive strength $R_{\perp}{ }^{c}$ of PA6-CF60, PA6-GF60 and PP-GF70 at $+23{ }^{\circ} \mathrm{C}$ and $+80{ }^{\circ} \mathrm{C}$

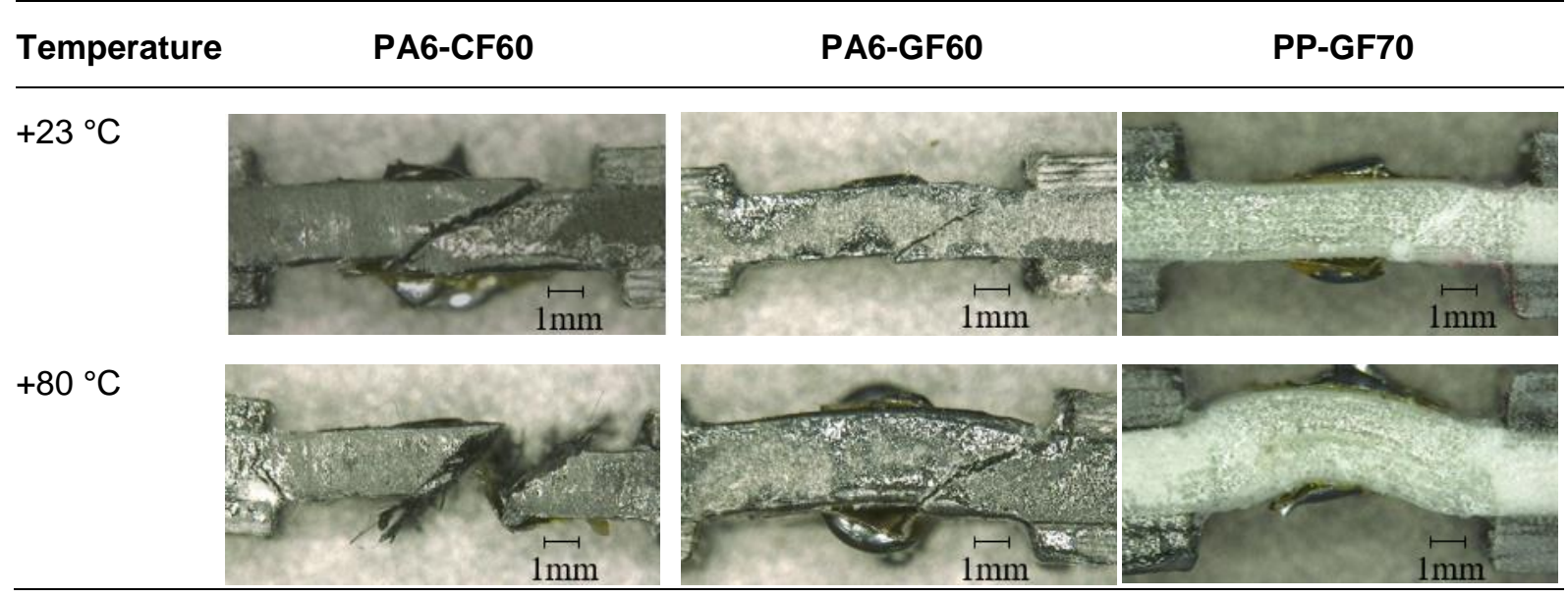

For the potential application of the FMC at higher temperatures for PP-GF70, further tests are required to verify whether the predicted failure stresses correspond to the actual multiaxial load despite the mixed fracture behaviour. Moreover, for all investigated materials further tests are necessary to analyse the transferability of temperature-dependent failure stresses from flat specimens to the loading of curved geometries, e.g. tube specimens. If this is not possible due to geometrical and manufacturing influences, the type of sample geometry from which the basic strengths are obtained could be weighed up on the basis of the geometry and manufacturing technology for the design of components. It should also be noted that the free gradient parameters $b_{\perp \|}, b_{\perp}^{\tau}$ and $\dot{m}$, which are assumed to be constant here, could also be temperature-dependent and thus would have to be determined for various temperatures in the investigated range.

\section{Conclusion and outlook}

The scripts created with Wolfram Mathematica in the context of this work provide a practical tool for the analytical description of the temperature dependence of the anisotropic strengths and stiffnesses of the investigated continuous fibre-reinforced semi-crystalline thermoplastics PA6-CF60, PA6-GF60 and PPGF70. Except for the fibre-parallel stiffnesses $E_{\|}{ }^{t}$ and $E_{\|}{ }^{c}$, the hyperbolic approach [2] is appropriate for all basic properties $\mathrm{E}_{\perp}{ }^{\mathrm{t}}, \mathrm{E}_{\perp}{ }^{\mathrm{c}}, \mathrm{G}_{\perp \|}, \mathrm{R}_{\|}{ }^{\mathrm{t}}, \mathrm{R}_{\|}{ }^{\mathrm{c}}, \mathrm{R}_{\perp}{ }^{\mathrm{t}}, \mathrm{R}_{\perp}{ }^{\mathrm{c}}$ and $\mathrm{R}_{\perp \|}$ as model of temperature dependence. An extension of the hyperbolic model, especially with regard to its application for wider temperature ranges and matrices with a larger number of softening phenomena, is suitable to consider the relevant mechanical effects for the corresponding application. A reduction of the necessary curve parameters $P_{j}$, $\mathrm{T}_{\mathrm{i}}$ and $\mathrm{k}_{\mathrm{i}}$ by averaging over all properties per parameter and material (fitting variant V2) causes a significant reduction of the prediction accuracy for the temperature dependence and should therefore not be applied. However, the test effort for determining predictive functions of temperature can be reduced by limiting the number of measurements to the relevant measurement temperatures with regard to DMA data according to fitting variant V3. The script-based implementation of the temperaturedependent basic strengths into Cuntze's Failure Mode Concept [14] carried out in the second section of the paper results in a model for predicting the failure behaviour under thermal and multiaxial mechanical stress. In order to verify the applicability of failure criteria based on uniaxial flat specimen, tests at different temperatures to multiaxial stress states in arbitrary geometries as well as further multiaxial tests on tube specimens according to recommendations of Puck [17] at different temperatures are necessary. Subsequently, failure analyses for multiaxially loaded FRTP structures can be performed on the basis 
of the scripts created here for the implementation of the hyperbolic temperature curves of mechanical properties into a mode-based failure concept.

\section{Acknowledgments}

This work was carried out within the Federal Cluster of Excellence EXC 1075 "MERGE Technologies for Multifunctional Lightweight Structures" and funded by the German Research Foundation (DFG). The financial support is gratefully acknowledged.

\section{References}

[1] Schramm, N.; Kroll, L.; Graetzl, T.: Temperature-dependent Failure Analysis of Fibre-reinforced Thermoplastics for Automotive Applications. Conference proceedings, 4th International Conference and Exhibition on Thermoplastic Composites, ITHEC 2018, Bremen: 30-31 October 2018, pp. 27-30.

[2] Gibson, A. G.; Torres, M.; Browne, T. N. A.; Feih, S.; Mouritz, A. P.: High temperature and fire behaviour of continuous glass fibre/polypropylene laminates. In: Composites Part A: Applied Science and Manufacturing 41 (2010) 9, pp. 1219-1231.

[3] Bauersachs, A.: Fortschrittlicher Leichtbau in Serie. OEM Supplier 2017, pp. 10-11.

[4] Kroll, L.; Meyer, M.; Nendel, W.; Schromair, M.: Highly Rigid Assembled Composite Structures with Continuous Fiber-Reinforced Thermoplastics for Automotive Applications. Procedia Manufacturing 33 (2019), pp. 224-231.

[5] Nendel, S.; Heinrich, H. J.; Kroll, L.: Resource-Efficient Production of Large-Scale Lightweight Structures. Conference proceedings, 3rd International Conference \& Exhibition on Thermoplastic Composites, ITHEC 2016, 11-12 October 2016 Bremen, pp. 72-73.

[6] Kuhnel, E.: Application of interfibre criteria on endless fibre reinforced thermoplastics. Aachen, Techn. Hochsch., Diss., 2010. IKV-Berichte aus der Kunststoffverarbeitung 211.

[7] Cuntze, R. G.; Freund, A.: The predictive capability of failure mode concept-based strength criteria for multidirectional laminates. Composites Science and Technology 64 (2004), pp. 343-377.

[8] Graetzl, T.; Dijk, Y.; Schramm, N.; Kroll, L.: Influence of the automotive paint shop on mechanical properties of continuous fibre-reinforced thermoplastics. Composite Structures 208 (2019), pp. 557-565.

[9] Hofbauer, D.: Multikriterielle Entscheidungsanalyse und Bauweisenvergleich von Faserverbundtechnologien für die Herstellung von Leichtbau-Karosseriestrukturen. München: Verlag Dr. Hut, 2018.

[10] Hufenbach, W.; Gude, M.; Boehm, R.; Zscheyge, M.: The effect of temperature on mechanical properties and failure behaviour of hybrid yarn textile-reinforced thermoplastics. Materials \& Design 32 (2011), pp. 4278-4288.

[11] Ehrenstein, G.; Riedel, G.; Trawiel, P.: Praxis der thermischen Analyse von Kunststoffen. 2. völlig überarb. Aufl., München: Hanser, 2003.

[12] Roesler, J.; Harders, H.; Baeker, M.: Mechanisches Verhalten der Werkstoffe. 4., überarb. u. erw. Aufl., 2013. Wiesbaden: Springer, 2012.

[13] Puck, A.: Failure Analysis of FRP Laminates by Means of Physically based Phenomenological Models. Composites Science and Technology 58 (1998) 7, pp. 1045-1067.

[14] Cuntze, R. G.: Efficient 3D and 2D failure conditions for UD laminae and their application within the verification of the laminate design. Composites Science and Technology 66 (2006), pp. 1081-1096.

[15] Materials Database. URL http://tools.celanese.com/. (accessed 30 Dec 2019).

[16] Schramm, N.; Kroll, L.; Iwan, S.; Trickov, V.: Process simulation and temperature-dependent failure analysis of continuous fibre-reinforced thermoplastics. Conference proceedings, 4th International MERGE Technologies Conference, IMTC 2019, pp. 69-70.

[17] Puck, A.: Die Zug-/Druck-Torsionsprüfung, 1982 (Kunststoffe 72). 